\title{
Jacques Derrida. Un seductor intelectual y sensorial. Diseminación de la deconstrucción a través de los cinco sentidos
}

\section{Jacques Derrida. An intellectual and sensory seducer. Dissemination of Deconstruction through all five senses}

\author{
Vicente MEdina GómEZ \\ Universidad Nacional de Tucumán, Argentina \\ d31251@hotmail.com
}

Recibido: 08-05-2012

Aceptado: 22-04-2013

\section{Resumen}

La transmisión del pensamiento de Jacques Derrida a otras disciplinas ha sido importante. Numerosas áreas han sido tierra fértil para sus propuestas. Esta cuestión es la que queremos abordar en este artículo. Pero no vamos a ocuparnos de todas ellas, sino de unas tan variadas y singulares como la restauración, la música, la moda y el cine. Este escrito pretende identificar de qué modo tales planteamientos han influido en dichas materias. En cada una de ellas su obra ha tenido su propio enfoque generando una constelación de deconstrucciones, en plural. Ello va en consonancia con el planteamiento que el filósofo hacía al sugerir que más correcto que hablar de la deconstrucción, es hablar de las deconstrucciones, ya que aquélla es, a su entender, plus d'une langue.

Palabras clave: Derrida, deconstrucción, filosofía, restauración, música, moda, cine.

\section{Abstract}

The transmission of the thought of Jacques Derrida to other disciplines has been important. Many areas have been fertile ground for their proposals. This issue is 
what we want to tackle in this article. But we will not deal with all of them, we will talk about some so varied and singulars as catering, music, fashion and cinema. This document try to identify in what way such approaches have influenced these subjects. In each one of those areas his work has had its own approach to creating a constellation of deconstructions, in the plural. This is in line with the approach that the philosopher was more correct in suggesting that talk of deconstruction deconstructions is that, as this is, in his view Plus d'une langue.

Keywords: Derrida, deconstruction, philosophy, cuisine, music, fashion, cinema.

\section{Jacques Derrida más allá del corpus filosófico}

La deconstrucción, el relevante pensamiento del filósofo argelino-francés Jacques Derrida, no solo ha cruzado fronteras geográficas sino también disciplinarias. Su discurso ha tenido una importante repercusión nacional, continental y transcontinental. Pero además, sus postulados se han diseminado en diversas áreas ajenas a la filosofía e incluso ha sido trascendental en algunas de ellas. La política, el derecho, la arquitectura o el arte se interesaron por sus propuestas. También lo han hecho otras tan singulares como la restauración, la música, la moda o el cine; son éstas las que llaman nuestra atención, porque al respecto poco se ha planteado. Derrida nada dijo acerca de las tres primeras; sin embargo, algo se ha ocupado de la última. De la magnitud que tuvo la onda expansiva de sus ideas en tales disciplinas es de lo que tratará este escrito.

Derrida siempre se mostró un tanto incrédulo sobre la aplicabilidad de sus teorías en otros campos, hasta tal punto que nunca supuso que esto llegara a suceder. Frente a su reticencia inicial, también era consciente de que la aplicación de sus estrategias en especialidades ajenas a la filosofía, tales como la arquitectura o la ley, "era absolutamente indispensable"1. Con el paso del tiempo, el devenir de los hechos y algunas manifestaciones extra disciplinarias ya a la vista, se vio impelido a augurar un prometedor futuro a sus propuestas. Incluso, y para su sorpresa, la influencia de sus planteamientos se estaba produciendo "no sólo en campos artísticos, como la arquitectura o la pintura, sino también en otros ajenos a las bellas artes o a la literatura", como la politología, el derecho o el cine ${ }^{2}$. Llegaba más allá de las instituciones académicas, como por ejemplo a la economía.

Consciente de la situación, Derrida ratificó finalmente lo que se intuía, planteaba y escribía, al menos en occidente, acerca de que su pensamiento había comenzado a atravesar los límites de la filosofía e influir en otras disciplinas. En una entrevista realizada por Carmen González-Marín en 1986, lo expresa del siguiente modo:

1 Derrida, J., No escribo sin luz artificial, Valladolid, Cuatro Ediciones, 1999, p. 152.

2 Derrida 1999, op. cit. (nota 1), pp. 55 y 149-157. 
Afirmaría que la deconstrucción no es esencialmente filosófica, y que no se limita a un trabajo del filósofo profesional sobre un corpus filosófico. La deconstrucción está en todas partes. Hoy se la toma en consideración por el hecho de que la temática -incluso la temática explícita de la deconstrucción bajo este nombre-, se despliega en campos que no tienen ninguna relación directa con la filosofía, no sólo en campos artísticos, como la arquitectura o la pintura, sino también en otros ajenos a las bellas artes o a la literatura. En Estados Unidos se habla de ella incluso en política, en el campo de las instituciones; así que la deconstrucción ni estaría limitada a los discursos filosóficos ${ }^{3}$.

Numerosos autores, críticos e historiadores como Amalia Quevedo, Michel Lisse, Peter Krieger o Cristina de Peretti y Paco Vidarte se han hecho eco de este planteamiento en sus escritos sobre el filósofo. Para Quevedo "la deconstrucción se mueve en campos más allá de la filosofía y la teoría, como la arquitectura, el arte, la política, las leyes, y sobre todo la literatura ${ }^{4}$. Lisse sugiere que a la propuesta derrideana "no solamente se la encuentra en los departamentos de filosofía o de letras, sino también en un dilatado campo cultural que va de la música a la moda pasando por la pintura o la arquitectura"5. Por su parte, Krieger sostiene que a "partir de los años ochenta, el ejercicio derrideano se convirtió en una verdadera moda de las investigaciones literarias, musicales, teológicas, pedagógicas, antropológicas y, con cierto retraso, también estéticas"6. Por su parte, de Peretti y Vidarte plantean que "con los años, el pensamiento de Derrida (...) ha ido afectando e incidiendo sobre un muy variado elenco de campos de aplicación teórica y práctica como son, además de la filosofía y la crítica literaria, la lingüística, el psicoanálisis, el derecho, la política, la historia, la arquitectura, la estética o la técnica: vídeo, cine, etc."7.

Destaquemos algunas frases de los pasajes citados por el hincapié que hacen en dos aspectos en los que nos interesa profundizar: la influencia de la deconstrucción derrideana en las disciplinas de las que nos vamos ocupar, y la tardanza en la llegada de tal discurso a las mismas. Todos coinciden en que la deconstrucción ha trascendido lo filosófico, que "se mueve más allá de la filosofía", señalando las numerosas y variadas disciplinas afectadas, sean humanísticas, científicas o técnicas. Pero solo Lisse subraya algunas de las que queremos estudiar aquí: la música y la moda. Por otro lado, queremos remarcar lo que sostiene Krieger, el hecho de que recién "a partir de los años ochenta, con cierto retraso," sus planteamientos fueron

\footnotetext{
3 Ibidem, p. 51.

4 Quevedo, A., De Foucault a Derrida. Pasando fugazmente por Deleuze y Guattari, Lyotard, Baudrillard, Navarra, EUNSA, 2001, p. 249.

5 Lisse, M., «Deconstrucciones», Volubilis, 7 (1999), p. 14.

${ }^{6}$ Krieger, P., «La deconstrucción de Jacques Derrida (1930-2004)», Anales del Instituto de investigaciones estéticas, 84, (2004), pp. 181 y 183.

7 Peretti Peñaranda, C. y Vidarte Fernández, F., Jacques Derrida (1930), Madrid, Ediciones del Orto, 1998, p. 15.
} 
asimilados por las disciplinas estéticas. Efectivamente, "con los años" como dicen Peretti y Vidarte, el pensamiento de Derrida ha ido "afectando a e incidiendo" en estas materias, entre las que incluimos las que son objeto de estudio. Un retraso temporal que toma como punto de partida de la deconstrucción filosófica las tres obras de Derrida publicadas en 1967: La voz y el fenómeno, La escritura y la diferencia y De la gramatología.

Pese a sus primeras reticencias respecto a que tales transferencias interdisciplinares llegaran a suceder, en cierta medida éstas eran algo anhelado por el filósofo. Más aún si tenemos en cuenta que fue muy habitual en él promover actividades y estudios de este tipo, con arquitectos, músicos, artistas, etc. Una posición que también era compartida por las instituciones que frecuentaba: el Groupe de recherche sur l'enseignement philosophique (GREPH) o el Collège International de Philosophie, institución de la cual fue su primer director ${ }^{8}$. Desde esta posición e instituciones, el filósofo insiste en que no se haga sólo filosofía, sino también actividades que resistan y provoquen a la misma hacia nuevas jugadas, hacia un nuevo espacio en el que ella no se reconozca ni siquiera a sí misma. Estas propuestas no deben ser vistas como actividades secundarias o marginales relacionadas a la filosofía, sino como el esfuerzo por reexaminar las relaciones de ésta con otras disciplinas e instituciones 9 .

Efectivamente, como pretende Derrida y como venimos señalando desde el inicio de este escrito, su discurso desborda la filosofía para afectar todas las disciplinas reseñadas. Incluso la diseminación de sus postulados alcanza inesperada y tangencialmente a la restauración, la música, la moda y el cine: las disciplinas de las que nos ocuparemos. En la década de los noventa, y con cierto retraso como se ha dicho, la deconstrucción derrideana comenzó a generar proposiciones tan singulares como la tortilla de patatas deconstruida, el disco Deconstruction o la película Deconstructing Harry. Estas propuestas inéditas vinculadas a la deconstrucción despiertan la curiosidad de saber por qué se ha producido este fenómeno o cómo se han llevado a cabo tales trasferencias interdisciplinarias.

Antes de adentrarnos en el asunto, sería conveniente hacer una doble aclaración, una terminológica y otra conceptual, sobre las que Derrida ha llamado la atención. Hablamos de las "influencias" de sus planteamientos en disciplinas extra filosóficas. Sin embargo, él prefiere el término "transferencia" o "diseminación" para referirse a ello. En segundo lugar, Derrida es reticente a hablar de influencias, porque

\footnotetext{
8 El Groupe de recherche sur l'enseignement philosophique, conocido como GREPH, fue un grupo de investigación sobre la enseñanza de la filosofía fundado en 1975 por Derrida. El Collège International de Philosophie fue fundado en 1983 en París por Derrida, François Châtelet, Jean-Pierre Faye y Dominique Lecourt como un centro de investigación y formación abierto al público. Ubicado en el $\mathrm{n}^{\circ}$ 1 de la rue Descartes de París, calle que da nombre a su revista Rue Descartes, funciona según el modelo de universidad abierta que organiza seminarios, conferencias y foros de reflexión.

9 Quevedo 2001, op. cit. (nota 4), p. 262.
} 
de ser así, tanto su pensamiento como la disciplina que lo alberga, tendrían una posición privilegiada en relación a las demás. Por esta razón y por su poca simpatía hacia las jerarquías intenta descubrir hasta qué punto la autoridad filosófica influye a una disciplina determinada, y de producirse tal situación, plantea revertirla o deconstruirla, ideas que expresa del siguiente modo:

... he aprendido de la filosofía que es un discurso hegemónico, estructuralmente hegemónico, que considera a todas las demás regiones discursivas dependientes de él. Y mediante recursos de deconstrucción de ese gesto hegemónico podemos empezar a ver en cada territorio, bien el que llamamos filosofía, lógica, política, bien el de las artes, la posibilidad de emanciparse de la hegemonía y autoridad del discurso filosófico. ${ }^{10}$

\section{El sabor de la deconstrucción}

En 1996, el cocinero Marc Singla propuso su singular tortilla de patatas deconstruida, durante un taller de cocina creativa denominado El Talaia ${ }^{11}$. El equipo de investigación de dicho taller se interesaba, entre otras cosas, por la aplicabilidad del concepto de la deconstrucción en la cocina. El mismo se llevó a cabo en el gerundense restaurante de Ferran Adrià El Bulli de Rosas, el cual comenzó a ofrecer la sorprendente proposición gastronómica a partir de 1998.

Con esta propuesta culinaria se estableció un especial punto de contacto no sólo entre la filosofía y la nouvelle cuisine, sino también con el arte, configurando entre ambas disciplinas un peculiar triángulo conceptual12. El planteamiento de Singla alcanzó tal difusión que, en 2007, le permitió a Adrià ser invitado a la duodécima edición de OOCUMENTA, una feria alemana de arte contemporáneo ${ }^{13}$.

\footnotetext{
10 Derrida 1999, op. cit. (nota 1), p. 150.

11 La tortilla de patatas deconstruida es una receta propuesta por Marc Singla de 1996 cuando era miembro colaborador de dicho taller, que duró desde 1995 hasta el 2002 y del que Singla llevó la dirección los últimos cuatro años. Dicha tortilla se atribuye erróneamente a Ferran Adrià, y el propio Adrià no ha tenido problema en reconocerlo. Regol, P., «La mar salada», [http://observaciongastronomica.blogspot.com/2009/07/la-mar-salada.html], (consultada la última vez el 12/07/2009).

AA.VV., «Marc Singla: la tortilla de patatas deconstruida», [http://homogastronomicus.wordpress. com/2011/11/08/marc-singla-la-tortilla-de-patatas-deconstruida/], (consultada la última vez el 08/11/2011).

12 Moriente, D., Poéticas arquitectónicas en el arte contemporáneo 1970-2008, Madrid, Cátedra, 2010, pp. 46-47.

13 Adrià, F., Los secretos de El Bulli. Recetas, técnicas y reflexiones, Madrid, Altaya, 1998, p. 336.

En 2007 Ferran Adrià fue invitado a participar en dOCUMENTA 12 por su director, Roger-Martin Buergel, muestra que se realiza cada cinco años en Kassel, Alemania. Su participación tuvo lugar entre el 16 de junio y el 23 de septiembre de 2007, es decir, en los cien días de la exposición, motivo por el que se la conoce también como "el museo de los cien días". La intervención consistió en que El Bulli,
} 
Preparadas por separado, la cebolla confitada, el huevo líquido y la espuma de patata caliente se sirven en capas en una copa de Martini y se come con cuchara de abajo a arriba, a fin de que la tortilla se acabe de crear en la boca con la mezcla de los tres sabores y las tres texturas ${ }^{14}$. De este modo, sigue siendo una tortilla de patatas totalmente identificable al paladar, siempre y cuando antes se haya comido una. El efecto memoria forma parte del juego gastronómico; la tortilla de patata tradicional es memoria y huella de la reconstruida ${ }^{15}$. Y es aquí donde entra en acción uno de los planteamientos del discurso derrideano: la huella. Dicha propuesta teóricofilosófica es simplificada, adaptada al discurso culinario y llevada a la práctica. Para Derrida toda huella retiene y compromete a la memoria a través de un doble vínculo: la presencia y ausencia. No existe en el presente, sino en un tiempo y un espacio que nunca está aquí, sino ausente. En este sentido, la tortilla deconstruida es una continuidad tanto de la tradicional como de otras creaciones experimentales precedentes propuestas por Adrià. Previas a la tortilla deconstruida fueron las espumas y todas las investigaciones sobre las texturas alimenticias, como su emblemática Menestra de texturas de 1994, plato que marcó el comienzo de su abstracción gastronómica ${ }^{16}$. Así también, aquella tortilla es huella de otras posteriores, puesto que ha inspirado versiones como la denominada Tortilla del siglo XXI del cocinero madrileño Paco Roncero ${ }^{17}$. Como sugiere Derrida, cada huella es la huella de una huella, y así hasta el infinito. No hay huella originaria. Es un factor de relación que se encadena. Ni última ni primera: es múltiple. Una huella nunca viene sola, no es jamás única, se engarza en una red de huellas.

En segundo lugar, la tortilla deconstruida al poner en cuestionamiento el binomio sólido-líquido propio de la gastronomía se hace eco del discurso derrideano de la revisión de los opuestos binarios o metafísicos. Un sistema de oposiciones que, para Derrida, caracteriza a la metafísica tradicional y que el pensamiento occidental ha asumido y utilizado desde siempre: presencia/ausencia, dentro/fuera, logos/escritura o sólido/líquido. En general, en esta estructura binaria el primer tér-

en Cala Montjoi, Cataluña, se convirtiese en el pabellón $\mathrm{G}$ de la muestra con un doble objetivo. Por un lado, poner en evidencia que la experiencia de El Bulli no puede descontextualizarse del restaurante y del lugar; por otro, plantear un debate acerca de las disciplinas artísticas no museables. Además, en el Fridericianum, el pabellón de exposición principal de la feria, cada día, durante los 100 días de dOCUMENTA podían cenar dos personas que ejercían de nexo de unión entre las dos sedes, Kassel y Cala Montjoi.

14 Adriá recuerda que el adjetivo que se pensaba emplear al principio era descompuesta, pero la palabra "descomposición en cocina no es nombre que quede muy bien". Por ello se optó por la palabra deconstrucción.

$15(08 / 11 / 2011)$.

16 Ibidem.

17 Fernández, M., «De la tortilla de patatas deconstruida a la cocina marinera», [http://www.expansion. com/2011/10/21/directivos/1319214432.html?a=38b4a3be704052f3c545a], (consultada la última vez el 21/11/2011). 
mino es el superior, el jerárquico, mientras que el segundo denota una pérdida de presencia18. Lo mismo ocurre gastronómicamente: primero se come, luego se bebe; primero lo sólido, luego lo líquido. Esto da a la comida un valor preponderante en relación a las bebidas. Es precisamente esa jerarquía de la comida y de ésta como un sólido lo que la deconstruida alterará.

Consecuente con el discurso derrideano, la tortilla deconstruida somete a revisión a la tradicional, la cual siempre se presenta como un alimento sólido. Como alternativa Singla propone una tortilla líquida, una plato para la cuchara19. Así, la axiomática sentencia, "lo sólido se come, lo líquido se bebe", presenta una tercera vía, una différance, un indecidible: "lo líquido se come". Una tortilla indeterminada que está a medio camino "entre" lo sólido y lo líquido.

La tortilla deconstruida también ha cuestionado uno de los aspectos fundamentales de dicho plato: su redondez. Ha arremetido contra su habitual y tradicional aspecto circular. Un perfil que es ideal, perfecto y cerrado y por tanto, deconstruible. La tortilla de patatas siempre se presentó redonda. A diferencia de ella, la deconstruida no tiene forma única y predeterminada, sino que se adapta a la de su receptáculo transitorio, la copa, en la que la aloja el chef en un momento concreto y para un comensal determinado. La variante reconstruida, a diferencia de la clásica, es unipersonal y por tanto, más que hablar de ella en singular, habría que hacerlo en plural: tortillas deconstruidas. Otra consonancia más con el discurso de Derrida, quien sugiere referirse a la deconstrucción en plural: deconstrucciones. En tal caso podríamos decir también plus d'une omelette.

Las fundamentaciones de esta propuesta por parte de sus autores han sido varias y diversas. En su libro Los Secretos de El Bulli Adrià comenta que emplea el concepto de la deconstrucción para deshacer analíticamente los alimentos para su percepción ${ }^{20}$. Produce en ellos cambios físicos de texturas más que una modificación de fondo químico, de aromas o gustos 21 . Lo mismo plantea con su naranja deconstruida, cuya pulpa es reducida a una confitura espesa que se vierte en unos moldes de silicona para recuperar su forma original 22 .

Además de los críticos culinarios y chefs que intentan establecer vínculos entre las propuestas de Adrià y las teorías de Derrida, están también los que plantean que

18 Peretti Peñaranda, C. de, Jacques Derrida. Texto y deconstrucción, Barcelona, Anthropos, 1989, pp. 30-31.

$19(12 / 07 / 2009)$.

20 Adrià 1998, op. cit. (nota 13), p. 336.

21 García del Moral, R., «Los paradigmas gastronómicos de la cocina contemporánea», [http://www.institutoroche.es/gastronomada/index.php?op=text2\&t=gastro_fondo\&id=17], (consultada la última vez el 30/11/2012)

22 Muñoz, A., «Más de 2.000 formas de deconstruir una naranja», [http://www. elpais.com/articulo/sociedad/2000/formas/deconstruir/naranja/elpepusoc/20111116], (consultada la última vez el 16/11/2011). 
ambas tienen difícil conexión. Entre otros argumentos, sostienen que en filosofía casi todo es primariamente racional y luego intervienen las impresiones sensoriales. En cambio, en gastronomía ocurre justamente lo contrario: primero se siente a través del olfato, el gusto y los receptores táctiles y luego se intelectualiza ${ }^{23}$.

\section{Deconstrucción y discografía}

La industria de la música tampoco se mantuvo al margen de este fenómeno mediático de la deconstrucción. Ejemplo de ello es la edición en 1997 del álbum Heaven Deconstruction de la banda suiza The Young Gods ${ }^{24}$. Un fenómeno discográfico que ha tenido otras manifestaciones como la del grupo noruego Cloroform ${ }^{25}$ con su disco denominado Deconstruction, de 1998. Igualmente, la cantante Meredith Brooks se hizo eco de la deconstrucción con su obra también titulada Deconstruction de 199926. Sin embargo, más allá del título, estas propuestas no tienen relación alguna con la filosofía derrideana. Tampoco aportan incursiones en esta disciplina, al menos deconstructivistas, algo que desde Arnold Schönberg con la introducción del sistema dodecafónico, a principios del siglo XX, no se ha vuelto a producir.

El término ha reaparecido recientemente en la música. El cantante Justin McRoberts 27 lo propone en su disco Deconstruction, de 2008. Devin Townsend 28 lo hace en su reciente disco Deconstruction, de junio de 2011. Este actual resurgimiento del vocablo deconstrucción en esta disciplina no es un hecho aislado; sirva de ejemplo la canción del grupo Fanfarlo también titulada Deconstruction, lanzada en octubre de 201129. Esta última referencia nos sirve además para señalar que, si bien antes hemos mencionado discografías completas deconstructivamente tituladas, hay innumerables canciones, dentro de otros álbumes, también denominadas bajo éste epígrafe.

\footnotetext{
$23(30 / 11 / 2012)$.

24 The Young Gods es una banda suiza de música industrial. Su singularidad se encuentra en que las letras de las canciones que una mezcla intertextuales o "injertuales" de términos en inglés, francés y alemán.

25 Cloroform es una banda de música alternativa noruega formada en 1998 en Stavanger.

26 Meredith Ann Brooks (1968-) cantautora y guitarrista estadounidense.

27 Justin McRoberts (1974-) cantautor, compositor y productor estadounidense.

28 Devin Townsend (1972-) multi-instrumentalista, vocalista y productor canadiense de metal progresivo con influencias de free jazz, blues, música industrial y clásica.

29 Fanfarlo es una banda londinense de indie pop formada en 2006 y cuyo nombre proviene de la novela de Charles Baudelaire, La Fanfarlo. La canción Deconstruction fue lanzada en web a la espera de su inclusión en nuevo disco. Web oficial www.fanfarlo.com.
} 
Una situación parecida a la de Fanfarlo es la del grupo Scritti Politti, liderado por Green Gartside, con su canción Jacques Derrida ${ }^{30}$. Esta banda fue la primera en vincular el nombre del filósofo al mundo de la música a principios de los años 80 .

En 1981 el grupo lanzó el single The Sweetest Girl en formato casete, seguido en 1982 por el single Faithless y el doble Asylums in Jerusalem/Jacques Derrida en formato vinilo ${ }^{31}$. Estas obras fueron reunidas en el álbum Songs to Remember, en formato vinilo y lanzado en agosto de 1982. Fue relanzado en 2001 en formato CD y por tercera vez en 2004.32 La canción Jacques Derrida fue nuevamente reeditada en el reciente disco recopilatorio de 2011 Absolute: The Best of Scritti Politti33.

El grupo se caracteriza por la música Post-punk, New Wave, Synthpop y Synthfunk, una sofisticada producción de estudio a la que Gartside une letras de canciones con juegos de palabras de estilo derrideano. Influenciado por lecturas deconstructivas vincula los estilos musicales citados con sutiles mensajes políticos y sociales integrados en sus canciones.

Dentro de este fenómeno musical, una singularidad la constituye el grupo finlandés Derrida. La banda tomó el apellido del filósofo como lexema de su grupo y la imagen del mismo para portada de uno de sus álbumes. Derrida está constituido actualmente, y tras numerosas altas y bajas de sus muchos miembros, por Atte Hakkinen, Juho Friman, Touko Renko, Petri Heiskanen y Ville Tura ${ }^{34}$. Fue fundada en 2004, en Tampere, tras la disolución del grupo Rainhold. Es un conjunto dedicado al Hardcore o Rock/Heavy metal y Punk como se definen en su web. Muchas de las letras de las canciones son poemas escritos por Hakkinen, quien recurre a las del Kalevala finlandés y viejos mitos locales.

Como recuerdan Hakkinen y Renko, ex estudiante de Historia, en la narración a-histórica de la banda que exponen en su web, ésta fue nombrada así en honor a Derrida, "tras su muerte". Confiesan que esto no es casualidad; eran conscientes de

\footnotetext{
30 Paul Julian Strohmeyer, alias Green Gartside (1955-, Cardiff), músico británico, cantante y compositor, es fundador y líder de la banda Scritti Politti, formada en 1977 en Yorkshire. Aunque ha habido cambios a lo largo de su historia, Gartside es el único miembro que ha permanecido desde su fundación. El nombre se usa generalmente para referirse a los escritos políticos del teórico marxista italiano Antonio Gramsci. Aunque el correcto en italiano sería Scritti Politici, éste fue sustituido por el actual por sonar más a rock and roll según palabras de su fundador.

31 Scritti Politti: Asylums in Jerusalem/Jacques Derrida, Londres, Rough Trade Record, 1982. (Vinilo).

32 Scritti Politti: Songs to Remember, Londres, $1^{\circ}$ ed. Rough Trade Record, 1982, LP Disco vinilo, $2^{\circ}$ ed. Londres, Virgin, 2001, Disco Compacto, $3^{\circ}$ ed. Londres, Virgin/Toshiba EMI, 2004. (Vinilo-CD). 33 Scritti Politti: Absolute: The Best of Scritti Politti, Londres, Virgin, 2011. (CD).

34 Atte Hakkinen en voz (desde 2004), Juho Friman en guitarra \& voz (desde 2004), Touko Renko en bajo \& voz (desde 2005), Petri Heiskanen en guitarra (2004-2007, 2009-presente), Ville Tura en batería (desde 2004).
} 
que "el filósofo tenía una gran repercusión en los medios de comunicación ese año". Incluso reconocen que, "en aquel momento estaba de moda referirse a él, al filósofo y padre de la deconstrucción, Jacques Derrida, al menos en algún grado".

Como consecuencia de su gira rusa en 2007, lanzaron el disco Russian tour edition 2007, siendo ilustrada la portada del mismo con la cara de Derrida ${ }^{35}$. Incluso se podría analizar hasta qué punto la imagen de su nuevo álbum, Vastakirjoituksia, es una alusión a algunos de los temas derrideanos, como la espectralidad y lo fantasmal. Un disco que cuenta con doce canciones singularmente numeradas de la A1 a la A6, y de la B1 a la B6, según corresponda al lado A o B del compacto36.

El fenómeno de la deconstrucción en la industria discográfica, a diferencia de lo ocurrido en las otras disciplinas, ha sido extenso y dilatado en el tiempo, como observamos con los discos reseñados, recientemente editados ${ }^{37}$. Sin embargo, no ha alcanzado la repercusión que ha tenido en otras como la gastronómica, la cual, pese a ser un hecho puntual, ha conseguido mayor difusión que la lograda por las múltiples propuestas musicales 38 .

\section{Pasarela deconstructivista}

También en moda hubo una manifestación deconstructivista, aunque más incipiente. Las propuestas pertenecen a un grupo de estudiantes belgas: los Seis de Amberes. Este conjunto de diseñadores de moda de vanguardia estaba constituido por Ann Demeulemeester, Walter Van Beirendonck, Dirk van Saene, Dries van Noten, Dirk Bikkembergs y Marina Yee ${ }^{39}$. Todos ellos fueron formados en la de Real Academia de Bellas Artes de Amberes en los años ochenta, bajo la enseñanza de Linda Loppa.

El look deconstructivista hizo furor a principios de los años noventa y surgió como reacción ante la conciencia de marcas y diseñadores de la década de los

\footnotetext{
35 El disco está constituido por la reunión de dos trabajos previos surgidos de conciertos; el demo Sokeat Mantrat, y un cassette Kuoleman makea tuoksu.

36 Se puede confrontar en las siguientes páginas: http://www.sweetcore.org/derrida y en http://www.myspace.com/derrida666.

37 Esta producción discográfica de diversos autores, tan prolífica y dilatada en el tiempo, es muy singular y puede constituir una interesante vía de estudio.

38 Al respecto leer. Bernal, A., «Música y deconstrucción», Enrahonar 38/39 (2007), pp. 171-180.

39 Se suele incluir a Martin Margiela dentro del grupo. También graduado en la Real Academia de Bellas Artes de Amberes, desde 1984 tiene su propia firma y basa su trabajo en el reciclaje y la transformación. Cfr. Mackenzie, M., «Deconstruccionismo», ...Ismos. Para entender la moda, Madrid, Turner libros, 2010, pp. 120-121; Stevenson, N., «Deconstrucción. Decada de 1990-2000», Moda. Historia de los diseño y estilos que han marcado época, Barcelona, Lunwerg, 2011, pp. 256-257; y Worsley, H., «El nuevo y modesto diseño belga. Deconstrucción y Amberes», 100 ideas que cambiaron la moda, Barcelona, Blume, 2011, pp. 188-189.
} 
ochenta. Se distingue por sus prendas sin terminar, con costuras y forros visibles, y colores grises predominantes. Se propone el gris y sus escalas como color intersticial, intermedio, entre el blanco y el negro. Éstos constituyen un opuesto binario acromático, empleados generalmente en las prendas reservadas a acontecimientos y ceremonias importantes ${ }^{40}$. Como alternativa a tales colores que actúan como opuestos metafísicos, los únicos del espectro de cromático, los seis de Amberes basándose en el discurso derrideano, proponen el gris como una tercera vía. Éste por su variedad de gamas y tonos actúa como un indecidible, un color que no se puede definir. A diferencia del blanco y el negro que se interpretan como absolutos, el gris es relativo. No hay un gris sino múltiples; en tal caso y en consonancia con el discurso derrideano deberíamos hablar de los grises, en plural.

Esta manifestación puntual acaecida en la década de los ochenta tuvo numerosos revivals, como por ejemplo, en 2011 en el Centro Superior de Diseño de Moda de Madrid. Bajo el lema Deconstrucción y a través del estudio y análisis de formas, texturas, colores de los tejidos y patrones de corte, un grupo de estudiantes realizó propuestas singulares bajo un pretexto, curiosamente más creativo que comercial. Plantearon trabajos experimentales, tanto formales como técnicos y basados en conocimientos morfológicos de los géneros y prendas ${ }^{41}$.

Pero, además de señalar las posibles influencias del pensamiento del filósofo en esta disciplina o las tendencias surgidas bajo la advocación deconstructivista, este escrito pretende llamar la atención sobre algo más: el interés del filósofo por la moda, pero no como un área de estudio, sino como usuario de la misma. Es cierto que no escribió sobre ella, pero no le pasaba desapercibida ni le era indiferente. Siempre bien vestido, elegante, alineado, arreglado, tenía de algún modo, a su manera, interés por ella. Sin embargo, su intención no era marcar tendencias, no era estar a la moda. Por eso, queremos reflexionar sobre un aspecto del filósofo, muy personal, y sobre el que poco se ha hecho hincapié. Se lo estudia desde muy diversas áreas, pero siempre su discurso, su pensamiento, sus planteamientos. De su imagen nadie parece ocuparse, cuando era algo importante para él. Derrida cuidaba mucho su apariencia, su aspecto y su vestir. Los que lo conocieron evocan anécdotas al respecto. Lo recuerdan como alguien coqueto. Cuidaba muy especialmente su estampa para la imagen, para la fotografía 42 . Al ver sus fotos descubrimos que lo suyo eran las camisas, claras y clásicas, generalmente lisas o de finas rayas y de

\footnotetext{
40 Powel, J, / Howell, V., Derrida para principiantes, Buenos Aires, Era naciente, 2004, p. 178.

41 Trabajos de alumnos de segundo año del curso 2010/2011 del Centro Superior de Moda de Madrid - DIMAD. Cfr. [http://www.csdmm.upm.es/documentos/fotos/album2Dimad2011/index.html], (consultada la última vez el 22/06/2011).

42 Cuenta Cristina de Peretti su experiencia durante su participación a un Coloquio de Cerisy-la-Salle (Francia) al que asistía Derrida. Le sorprendió ver el interés con que preparaba y elegía su vestuario para el día anunciado en que se llevaría a cabo la foto oficial del encuentro.
} 
mangas largas, los pantalones de vestir y zapatos en general. Para las ocasiones importantes, el traje o la americana, las corbatas o los fulares al cuello. Abrigos e impermeables largos. Colores sobrios en camisas y jersey; blancos, celestes y azules. Excepcionalmente el rojo, pero un rojo indeterminado, tipo burdeos u oscuro anaranjado en alguna camisa o fular. Beige, marrones y grises claros $u$ oscuros en americanas, trajes, abrigos e impermeables. El amarillo y el verde están ausentes en su vestuario. En contadas ocasiones los cuadros en americanas o bufandas. Entre los complementos, la pipa siempre en mano pone la nota final a su elegancia. Nada de abalorios, ni anillos. Solo gafas por necesidad o coquetería. Jamás sombreros; el pelo con peinado indefinido. Siempre peinado sin raya, pero peinado. Las camisas de mangas cortas, las camisetas, los jeans y las zapatillas no eran una opción en su armario. Al parecer, le eran ajenos desde la niñez. Incluso, durante las prácticas deportivas le vemos utilizar camisas. Insistimos, su vestuario y manera de vestir merecen una atención que poco se ha prestado. La ropa y el buen atavío eran importante para él, pero ¿la moda también? Sería importante aclarar esta cuestión antes de abordar cualquier estudio al respecto. Igualmente, llamamos la atención sobre la importancia de diferenciar lo que podemos denominar "costura deconstructivista", tema tratado en la primera parte de este apartado, y el "atuendo" personal de Derrida, tan poco deconstructivo.

\section{Deconstrucción y cinematografía}

El fenómeno de la deconstrucción también abrazó al cine, no sólo por los planteamientos que Derrida hizo acerca de esta disciplina, sino también porque algunos directores se hicieron eco de esta propuesta filosófica, o al menos de su terminología. Deconstructing Harry, dirigida por Woody Allen y estrenada en 1997 es un ejemplo de ellas. La misma no es sólo un título que utiliza un término en boga. Como sugiere Maurizio Ferraris el film implica una clara referencia derrideana, a la vez que no deja de sorprenderle que el filósofo tenga semejante resonancia 43 .

Numerosos planteamientos del guión podrían tener como referente algunos discursos derrideanos. La biografía de Harry Block, personaje principal de la película, podría vincularse en ciertos aspectos con la de Derrida. Block es un escritor judío que como su hermana sugiere, "analiza y cuestiona constantemente su judaísmo" 44. Para Harry, la tradición judía, como cualquier tradición en general es cuestionable, puesto que la ve como "la ilusión de lo permanente". Plantea las religiones "como clubes exclusivistas que fomentan el concepto de los otros", es decir, identifican a los que no forman parte de dicho clan y por tanto, son objeto de persecución. Estas

\footnotetext{
43 Ferraris, M., Jackie Derrida. Retrato de memoria, Bogotá, Siglo del hombre, 2007, pp. 59-60.

${ }^{44}$ Los intertextos entre comillas pertenecen al guión de los personajes en la película.
} 
enseñan "muy bien a quién odiar". Estos planteamientos acerca de la religión son comparables a algunos de los derrideanos. El filósofo también cuestiona a su manera, el exclusivismo que pretenden tener las religiones. También tiene gran conciencia sobre el judaísmo, la tradición dentro de la que creció, y en gran parte, de modo inconsciente. Incluso si tuviéramos la certeza de que Allen leyó a Derrida, algunas historias del personaje podrían entenderse como un guiño a ciertos acontecimientos ocurridos en la vida del filósofo argelino. Por ejemplo, el pasaje en el que Harry expresa, "la misma universidad de Adair que me expulsó hace años ahora quiera homenajearme". Esta historia es parecida a la que Derrida vivió con el rechazo de algunos de sus "amigos" en círculos universitarios parisinos a que ingresara en ellos, o incluso el poco reconocimiento que se le dio al principio en Francia, lo cual fue posteriormente revocado 45 . Él mismo destaca constantemente en sus escritos su individualidad y confinamiento intelectual o su vínculo conflictivo con la Universidad 46.

A Harry no le interesa la universidad. Él solo quiere ser escritor. Lo único que le importa es escribir. Igualmente a Derrida, en la secundaria, no le interesaba el instituto, solo la literatura y por ello, pese a su expulsión, se dedicaba a la lectura y su formación autodidacta leyendo a Rousseau y Nietzsche, sus primeros intereses filosóficos. Luego vinieron Bergson, Sartre y su predilección por Gide, Válery y Camus. Una situación parecida vivió en los años de transición a la espera de aprobar los exámenes de la Khagne para entrar en la École Normale Supérieure de París; leía a Kierkegaard, Heidegger, Simone Weil, Marcel y Merleau-Ponty.

Otro vínculo que se podría establecer con el discurso derrideano es el guión asignado al personaje del actor Mel, quien en el film se plantea desenfocado o borroso. Según el director de rodaje "está fuera de foco; está desenfocado". El ayudante de cámara "intenta enfocarle en el visor y no hay manera; no puede hacer nada", sugiriendo que no puede "ajustarlo para una cosa y para otra no". El equipo de rodaje tiene que ver las cosas claras para rodar, ya sea en blanco o en negro, puesto que el gris intermedio, indefinido, impreciso no les sirve, los confunde, los marea. Necesitan aclararlo. La solución al problema la da el médico pese a comentar: "nunca he visto nada igual". Sostiene que "no le ocurre nada, salvo que está desenfocado". Y propone con ironía una solución que es propia de aquéllas que las estrategias derrideanas suelen cuestionar. Sugiere que los demás se pongan gafas correctoras. Pero no cualquier tipo de gafas, sino las mismas que usa Harry, las que

\footnotetext{
45 En la década de 1970, en concomitancia con la difusión del pensamiento de Derrida, se multiplican los enfrentamientos y las controversias. Se teme, como mínimo, que la deconstrucción, como práctica ideal, dé lugar a una escolástica repetitiva y fútil. La deconstrucción no logró, como sí lo hizo la fenomenología, transformarse en disciplina. Cfr. Ferraris, M., Introducción a Derrida, Buenos Aires, Amorrortu editores, 2006, p. 111.

46 Ferraris 2006, op. cit. (nota 45), p. 112.
} 
les permitirán a todos ver de la misma manera, hablar el mismo lenguaje y entender la realidad desde la misma perspectiva que Mel. La síntesis de este planteamiento la hace el psicólogo de Harry, abriendo un doble juego de interpretación con el siguiente comentario: "Así que, a pesar de que los niños no quieren ponerse las gafas les obligan. ¿Usted espera que el mundo se adapte a la distorsión de usted?" El especialista plantea que, por un lado, el desenfocado no tiene por qué enfocarse o aclararse: quien lo vea desenfocado o borroso debe adaptarse a su realidad y una solución es que los demás se pongan gafas para verle "bien". Por otro lado, la idea recuerda que desde niños nos enseñan a adaptarnos al mundo metafísico del binomio y cuando hay algo diferente o distinto dentro del binomio, que no pueden explicar los mayores, nos ponen unas gafas mentales para que adaptemos lo desenfocado a dichos pares de opuestos. Soluciones de este tipo son a las que las estrategias derrideanas someterán a revisión.

Pero hay otros aspectos por los que se podrían vincular esta película a la deconstrucción derrideana. Allen utiliza la historia de la película Fresas salvajes de Ingmar Bergman, como referencia y huella de la suya, entendiendo el concepto de huella como lo plantea Derrida. Incluso se podría explorar en qué medida hace un trabajo de injerto, propio de las estrategias derrideanas en la obra de Bergman.

Si bien el título de la película utiliza el término deconstructing, recién y solo al final de la misma Allen hace aparecer el mismo, certificando esta producción al fenómeno. Ocurre cuando la estudiante Mary de la Universidad de Adair le recuerda a Harry que es ella la que está deconstructing su vida, analizando los personajes que la constituyen, mirándolo desde diversos ángulos y perspectivas ${ }^{47}$.

Al margen de este episodio puntual y de esta comercial búsqueda de contacto unilateral, de este encuentro terminológico entre lo cinematográfico y lo derrideano, cabe destacar que Derrida ha demostrado gran interés por las disciplinas de la imagen, como el cine. Lo hizo tanto a través de diversos escritos, como de numerosas participaciones en películas en las cuales era tema y/o actor.

En 1983 hace su primera aparición en cámara en L'Appel du Silence, un documental dirigido por Phillippe Alfonsi, dentro del ciclo Resistencia: arte contra el apartheid de la cadena 2 de televisión francesa. Seguirán Ghost Dance en 1984 dirigida y producida por Ken McMullen, con la participación de la actriz francesa Pascale Ogier, y luego el documental Caryl Chessman, l'ecriture contre la mort, en 1987, dirigido por Jean-Christophe Rosé. Tras estas incursiones vendrá una serie de películas documentales donde Derrida es actor y tema de las mismas. D'ailleurs Derrida de Safaa Fathy es una de ellas. Rodada entre 1998 y 1999 tuvo la postpro-

\footnotetext{
47 La traducción al español del título de la película fue Desmontando a Harry, puesto que, como analizaremos posteriormente, el término deconstrucción todavía no había sido reconocido por la Real Academia Española de la lengua. La película es de 1997 y el término se incorpora al diccionario de la RAE en su vigésimo segunda edición de 2001.
} 
ducción adicional del libro Rodar las palabras ${ }^{48}$ escrito por el propio Derrida y Fathy en 2000. Otra más es la película estadounidense Derrida de Kirby Dick y Amy Ziering Kofman, rodada entre 1994 y 200249 . Además habría que considerar las numerosas entrevistas televisivas y videoconferencias académicas en las que Derrida ha participado, como las llevadas a cabo por Alan Montefiore en 1992, por Bernard Stiegler en 1996 o el documental dedicado al filósofo por José María Ripalda, Cristina de Peretti, Francisco Vidarte en 1997. Incluso fue objeto de instalaciones mediáticas como Disturbance (among the jars), una instalación de video con 7 monitores en transmisión simultánea, montada en 1988 por el artista norteamericano Gary Hill50. Dicha muestra, perteneciente a la colección del Centro George Pompidou, fue expuesta por primera vez en 1989 en el Museo de Arte Moderno de Villeneuve d'Ascq51.

Además de lo expuesto, es relevante señalar que el cine fue un hobby importante para Derrida, puesto que era un gran consumidor de películas de todo tipo, como él mismo reconoce. Sin embargo, no solía mantener recuerdos precisos de este "gran arte popular", como él lo denomina. Considera que es un modo de cultura que no le "deja rastros", y por tanto no lo utiliza como referencia de sus obras filosóficas. A pesar de ello, hace algunas precisiones sobre esta disciplina. Las mismas parecieran no haber caído en tierra fértil, al menos de momento, si tenemos en cuenta la poca aplicación que han tenido en este oficio a diferencia de lo que ocurre en otros, como vimos. Tampoco podemos decir que hayan caído en saco roto. Algunos directores experimentales como Ken McMullen han hecho algunas propuestas cinematográficas documentales que podríamos vincular a los discursos derrideanos ${ }^{52}$.

\footnotetext{
48 Derrida, J. / Fathy, S., Rodar las palabras. Al borde de un film, Madrid, Arena libros, 2004, 160 pp. 49 Amy Ziering Kofman fue una de sus estudiantes de Yale en 1984. Tras una conferencia a mediados de los 90 se acercó y le propuso participar en un documental que luego termino siendo dicha película. Powell 2008, op. cit. (nota 47), p. 274.

${ }^{50}$ Cfr.: http://hydra.humanities.uci.edu/derrida/media.html, (consultada por última vez el 07/12/2012). Dentro de esta página recomendamos consultar el link Special Collections at UC Irvine para acceder a la Guide to the Jacques Derrida Papers del Critical Theory Archive de la Irvine Californian University.

51 Expuesta entre el 19 de enero y el 19 de febrero de 1989 en el Museo de Villeneuve d'Ascq, dicha muestra fue posteriormente reunida con otras instalaciones en un ciclo de exposición grupal itinerante, organizada por el Centro Pompidou titulada Passages de l'image llevada a cabo entre el 18 de septiembre de 1990 y el 13 de enero de 1991 en el Centro Pompidou de París, entre el 12 de febrero y el 28 de marzo de 1991 en el Centre Cultural Fundació Caixa de Pensions de Barcelona, entre el 1 de junio y el 27 de octubre de 1991 en el Wexner Art Center de Columbus y finalmente, entre el 6 de febrero y el 12 de abril de 1992 en el Museo de Arte Moderno de San Francisco. Cfr. Hill, G. et al., Disturbance. (among the jars), Villeneuve d'Ascq, Musée d'art Moderne, 1989 ; AA.VV., Passages de l'image, París, Editions du Centre Pompidou, 1990. Versión castellano/catalán: Passages de l'image, Barcelona, Fundació Caixa de Pensions, 1991, pp. 280.

52 Ken McMullen (1948-) director de cine y artista inglés. Sus películas y sus documentales son de amplia difusión y sus obras de arte han sido expuestas en Europa, Estados Unidos y Oriente. Sus películas y documentales se centran en la filosofía, la historia, el psicoanálisis y la literatura.
} 
Por ejemplo, Arrows of Time, su último trabajo, consta de 40 elementos intercambiables vinculados con la literatura, la filosofía y la física contemporánea, los cuales se combinan en un orden diferente en cada muestra.

Si bien no es objetivo de este escrito ocuparse en profundidad de las influencias del pensamiento derrideano en el cine, tampoco podíamos pasar por alto o dejar de mencionar que Derrida ha realizado apreciaciones al respecto. Referenciamos algunos de sus pasajes en relación a este tema, los cuales pueden constituir otra importante vía de estudio 53 .

A Derrida le interesa el cine porque la experiencia cinematográfica pertenece a la idea de la espectralidad y por tanto la relaciona "con todo lo que se puede decir del espectro en psicoanálisis o con la naturaleza misma de la huella". Incluso plantea que al escribir un texto "proyecta una suerte de film", recordando que lo que le interesa en la escritura es menos "el contenido que la forma: la composición, el ritmo, el esbozo de una narratividad particular" 54 . Recuerda que el cine, la película y hasta la televisión, han cambiado profundamente nuestra relación con la imagen y el habla, como lo expresa en Ecografías de la televisión.

Para Derrida lo filmado tiene que ver también, en muchas situaciones, con lo oprimido o desplazado. Lamenta, por ejemplo, que en el derecho occidental "el documento filmado no tiene valor de prueba". Ello demuestra que la idea occidental de creencia tiene "una desconfianza irreductible hacia la imagen en general y hacia la imagen filmada en particular". Pone así en evidencia que solo "la escritura en su presencia real tienen derecho a la creencia" 55 . Esto le lleva a concluir y recordar que el cine es un arte de la presencia de la voz, del habla y por tanto se puede relacionar a uno de sus más importantes planteamientos: el logofonocentrismo.

No obstante todo lo expuesto, no se deja de suponer que debe de haber tenido ciertas reservas hacia esta disciplina. El cine, como tal, es una industria y por tanto vinculada al capital y a la industrialización. No dudamos que para Derrida esto haya sido bastante cuestionable o deconstruible.

\footnotetext{
53 Derrida ha expresado sus ideas acerca del cine y la televisión en reiteradas oportunidades, pero hay dos entrevistas donde aborda la cuestión que recomendamos leer: Derrida, J. / Stiegler, B., Ecografías de la televisión: entrevistas filmadas, Buenos Aires, Eudeba, 1998, pp. 200. Y Derrida, J., «Le cinéma et ses fantômes», Cahiers du cinéma, 556, (2001), p. 78. Este texto es el resultado de dos entrevistas con Derrida: una fue realizada en París el 10 de julio de 1998, por Antoine de Baecque y Thierry Jousse, la otra, el 6 de noviembre de 2000, por Thierry Jousse. Transcripción y edición Stéphane Delorme. Entrevista publicada y traducida nuevamente en la revista Desobra. Derrida, J., «El cine y sus fantasmas (Conversación con Jacques Derrida)», Desobra. Pensamiento, Arte, Política, 1 (2002), pp. 93-106.

54 Derrida 2002, op. cit. (nota 54), p. 93-106.

55 Ibidem, p. 93-106.
} 


\section{Acerca de estas seductoras influencias}

El pensamiento de Derrida tuvo una intensa y extensa influencia. Ha ido más allá de la disciplina a la que él estaba vinculado, abarcado a otras áreas y generado con esa expansión numerosas variantes de su discurso, como hemos podido comprobar. Este uso y abuso provocó cierta confusión e incredulidad acerca de la propuesta y sus influencias. Incluso en muchas ocasiones se llegó a anunciar la muerte de la deconstrucción, considerándola moda pasajera o capricho momentáneo. Especialmente al verla vinculada a algunas de las disciplinas analizadas.

Como sugiere Krieger el pensamiento derrideano produjo entre sus seguidores casi una tendencia, donde los interesados retomaban y modificaban libremente los fragmentos filosóficos del maestro. Esto hizo que cada reducción de su pensamiento a un estereotipo personal sembrara dudas hacia el deconstructivismo 56 .

Ante esta situación Derrida recordó que "hay deconstrucción y «deconstrucción» (...) No lo olvidemos nunca si queremos no mezclar todas las deconstrucciones de este momento. Y del mundo"57. De este modo dejaba claro que todas aquellas propuestas eran posibles, lo cual era consecuente con su planteamiento de que la deconstrucción es plus d'une langue. En este sentido esta apertura interdisciplinaria de su discurso permitía ratificarlo. La "transferencia" de sus postulados a otras materias había hecho efectiva las "reconstrucciones" a las que se refería Derrida y no solo en filosofía, sino también fuera del corpus filosófico.

Ante tal diseminado panorama es comprensible que haya habido confusión e incredulidad al respecto. Sensaciones incrementadas por la denunciada superficialidad con que se trataba el tema en disciplinas como la gastronomía, la moda o la música. Pero para cuando el planteamiento derrideano comienza a extenderse a estas áreas, ya se había consolidado y con base sólida en la filosofía. Incluso antes de extenderse a ellas lo había hecho geográficamente, lo cual ampliaba y fortalecía sus cimientos sobre los que se apoyarían las demás disciplinas. A finales de los sesenta y principios de los setenta, entre controversias y aplausos la dispersión de la deconstrucción filosófica fue mundial, pese a las predicciones, incluso las del propio filósofo. Europa y Estados Unidos se habían hecho eco de su discurso tanto a través de la filosofía, como de las variadas disciplinas mencionadas. Una diseminación beneficiada por los importantes cambios sociales, políticos y culturales en ambas partes.

En Europa habían disminuido las resistencias de los filósofos continentales, especialmente las de los hermeneutas, aunque subsistían las sostenidas por los ana-

\footnotetext{
56 Krieger 2004, op. cit. (nota 7), p. 187.

57 Derrida, J., Le toucher, Jean-Luc Nancy, París, Galilée, 2000, p. 74. Apud. Peretti Peñaranda, C. de, «Herencias de Derrida», Isegoría, 32 (2005), p 133.
} 
líticos. Paralelamente a ello se multiplicaban las ediciones de sus libros, que se publicaban a un ritmo apremiante, reelaborando conferencias y seminarios.

En Francia, el auge de su pensamiento coincidió con los movimientos sociales y políticos que hicieron reconocer al país que su historia de independencia europea, revolución y colonialismo finalmente había acabado. El postmodernismo desilusionado de su evolución se manifiesta en La condición posmoderna de François Lyotard. Éste se presentaba como un anuncio del fin de los grandes relatos de los que se había nutrido el discurso filosófico de la modernidad. Además, el planteamiento deconstructivista comenzaba a interesar e implicar a otros pensadores contemporáneos locales como Jean-Luc Nancy.

Por su parte, en Estados Unidos había tanta influencia de la filosofía analítica en la segunda mitad de la década de los sesenta, que una inyección de nueva filosofía europea continental parecía necesaria. En este contexto llegó el pensamiento de Derrida en octubre de 1966. Y lo hizo con un desembarco apoteósico en el Coloquio internacional sobre lenguajes críticos y las ciencias del hombre, celebrado en la Universidad John Hopkins de Baltimore. A partir del mismo se generó una creciente atención hacia la deconstrucción en dicho país ${ }^{58}$.

El crítico literario Paul De Man, asistente al congreso, fue quien popularizó la obra del filósofo argelino en Estados Unidos. Procedente de Bélgica y anglo-franco parlante fue el punto de articulación justa para Derrida. Junto a él y a los críticos literarios Hillis Miller, Geoffrey Hartman y Harold Bloom, Derrida empezó a enseñar en Yale a partir de 1975 dando inicio a la Escuela de Yale 59 . La misma fue el motor de difusión de sus ideas y de la deconstrucción en dicho país.

Si bien la fama internacional de Derrida surgió en sentido estricto cuando llegó a Estados Unidos y tras su debut revolucionario en el coloquio de Baltimore, la misma se vio reforzada con las publicaciones de sus tres libros de 1967: La escritura y la diferencia, De la gramatología y La voz y el fenómeno. Sin embargo, no hay conocimiento de que los involucrados en las disciplinas escogidas hayan leído los trabajos del filósofo. No obstante, casi todos estaban al tanto de la propuesta filosófica e incluso del filósofo.

Una primera aproximación al tema parecía sugerir que tales influencias en estas disciplinas habrían sido más bien superficiales. Sin embargo, tal aparente ligereza no lo sería tanto en la música ni mucho menos en el cine. En estas áreas, como también ocurre en otras también artísticas pero más académicas, como la pintura o la arquitectura, tanto músicos, directores, pintores como arquitectos se han interesado y leído los discursos del filósofo. De ello tenemos pruebas. En cambio no las hay

\footnotetext{
58 Participaron, entre otros, G. Poulet, L. Goldmann, E. Donato, T. Todorov, R. Barthes, N. Ruwet, J. Lacan y Derrida.

59 La Escuela de Yale fue anunciada por primera vez por Hillis Miller en el New Republic en noviembre de 1975 y en el Georgia Review en 1976.
} 
para implicar a chefs y diseñadores de moda. Pero esta supuesta superficialidad, en lugar de frenar o quitar relevancia a este trabajo o a las materias implicadas. lleva a esgrimir el siguiente argumento.

Se ha visto y expuesto cómo Derrida ha ido seduciendo intelectualmente y ganando territorio con su discurso en diversos países. Pero tal galanteo no era solo intelectual sino también sensorial. De ello se encargaban las disciplinas estudiadas sirviendo de enlace para transferir el pensamiento derrideano a un interlocutor o receptor final y sensible60. Sin embargo el proceso no fue nada fácil, tanto por los numerosos altibajos como por las opiniones de partidarios y detractores.

Como sugerimos, el vínculo de la deconstrucción con algunas de las disciplinas analizadas ha hecho considerar a aquellas, en ocasiones, una moda pasajera o capricho momentáneo. Incluso se ha acusado a esta relación de haber contribuido al descrédito de la propuesta filosófica. Sin embargo, tal conexión, por la popularidad de estas materias ha sido la que más ha hecho posible la difusión y el conocimiento masivo del pensamiento derrideano. Este enlace ha contribuido a alcanzar el objetivo de la deconstrucción de ser plus d'une langue ya iniciado por otras disciplinas más académicas. El mismo ha sido mucho más efectivo para su diseminación que la relación entablada con disciplinas institucionalizadas, artísticas o no, incluso cuando las primeras puedan tener mayor alcance que otras como el derecho o la economía. Sin embargo, todas ellas están circunscriptas a círculos más erudito y selectos, y por tanto, jerarquizados socialmente. En cierta medida la asociación con estas disciplinas no solo ha posibilitado la mayor diseminación del pensamiento derrideano, sino también ha servido para constituirlo en una propuesta que no privilegia o jerarquiza a ninguna asignatura sobre las demás. Des-jerarquización y desterritorialización geográfica y disciplinaria han ido de la mano con las propuestas derrideanas para alcanzar el máximo esparcimiento de éstas y convertirlas en una verdadera plus d'une langue. A esas dos estrategias han contribuido con mérito y éxito las disciplinas abordadas en este escrito: la gastronomía, la moda, la música y el cine. De este modo, las estrategias derrideanas se dispersaban y abarcaban tanto a la razón como a lo sensitivo. Quien no era inseminado a través del entendimiento lo era por los sentidos: el gusto, el olfato, el oído, la vista y el tacto. La comida, la ropa, la música y el cine han sido cuatro herramientas poderosas de seducción al servicio de las estrategias deconstructivistas. Lo racional y lo empírico parecían darse la mano en el discurso derrideano alcanzando un objetivo largamente anhelado desde las propuestas kantianas.

Derrida era un seductor nato con su imagen, su palabra y sus pensamientos. Su cuidado aspecto y su buen vestir, no eran solo una cuestión de elegancia y coquete-

60 En este sentido es importante resaltar que no se trata de una "deconstrucción aplicada". Hay que evitar considerar este planteamiento de este modo, puesto que, en tal caso se cometería el error de relacionar la deconstrucción a la hermenéutica, por ejemplo. 
ría masculina, sino complementos de su palabra y sus discursos, para tener cautiva la atención de su interlocutor e inseminarlo intelectualmente. Y cuando no alcanzaba su objetivo por la vía intelectual o racional lo abordaba por lo sensorial. Seducía y conquistaba cada uno de los sentidos de su receptor con sus pensamientos y propuestas, camuflados a través de la gastronomía, la música, la moda y el cine. Las mismas han sido unas importantes herramientas empleadas para la diseminación y transferencia de su pensamiento de modo des-jerarquizado y para la realización de éste en un efectivo plus d'une langue.

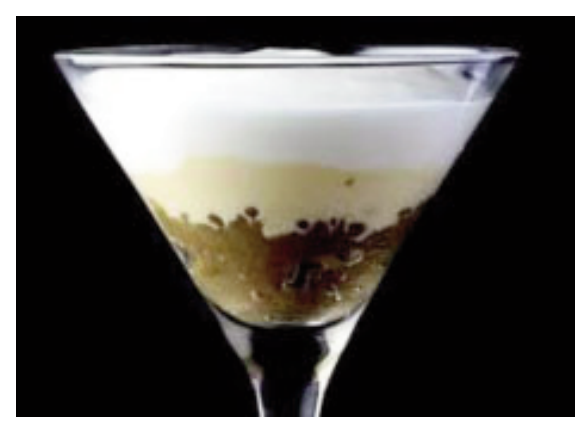

Marc Singla: Tortilla de patatas deconstruida

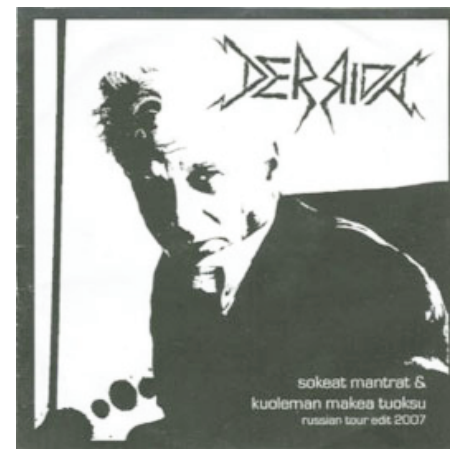

Derrida: Russian Tour edition 2007 